\title{
Cardiac Tumors in the Neonatal Period: Clinical Features and Echocardiographic Evaluation
}

\author{
${ }^{1}$ Monica Hăşmăşanu, ${ }^{2}$ Simona Oprița, ${ }^{3}$ Tünde Kovacs, ${ }^{4}$ Sorin Andreica, ${ }^{5}$ Melinda Mátyás, \\ ${ }^{6}$ Estera Decean, ${ }^{7}$ Florin Stamatian, ${ }^{8}$ Gabriela Zaharie
}

\begin{abstract}
Introduction: Primary cardiac tumors are rare in the fetal and neonatal period $(0.0017-0.28 \%)$, but considerably more frequent than the metastatic ones; most of them are benign. The objective of this study was to analyze the clinical and echocardiographic features of cardiac tumors during the neonatal period.
\end{abstract}

Case presentations: In the period of 6 years (2007-2012), we diagnosed five newborns with cardiac tumors of which two newborns with left ventricle tumors suggestive of rhabdomyomas, both diagnosed in utero; a newborn with multiple heart and brain tumors, suggestive of tuberous sclerosis, who died after 24 days; a newborn with tricuspid valve papillary fibroelastoma, hemodynamically stable during the monitoring; and a newborn of the mother with high-risk pregnancy with a single right atrial tumor.

Conclusion: Cardiac tumors are rare but have good prognosis when not accompanied by arrhythmias or hemodynamic changes. Echocardiographic evaluation is an effective method for the diagnosis and monitoring of patients with cardiac tumors.

Keywords: Cardiac tumor, Echocardiography, Newborn.

How to cite this article: Hăşmăşanu $M$, Opriţa $S$, Kovacs $T$, Andreica S, Mátyás M, Decean E, Stamatian F, Zaharie G. Cardiac Tumors in the Neonatal Period: Clinical Features and Echocardiographic Evaluation. Donald School J Ultrasound Obstet Gynecol 2014;8(2):201-207.

Source of support: Nil

Conflict of interest: None

\section{INTRODUCTION}

Primary cardiac tumors are rare in the fetal and neonatal period, with an incidence of 0.0017 to $0.28 \%{ }^{1,2}$ Compared

\footnotetext{
1,3,4 Assistant Lecturer, ${ }^{2}$ Senior Physician ${ }^{5}$ Lecturer, ${ }^{6}$ Resident ${ }^{7}$ Professor and Head, ${ }^{8}$ Professor

1,4-6,8 Department of Neonatology, University of Medicine and Pharmacy, Cluj-Napoca, Romania

${ }^{2}$ Department of Cardiovascular Surgery, Cardiology Institute Cluj-Napoca, Romania

${ }^{3}$ Department of Obstetrics and Gynecology I, University of Medicine and Pharmacy, Cluj-Napoca, Romania

${ }^{7}$ Department of Obstetrics and Gynecology I, Director, Mother and Child Department, University of Medicine and Pharmacy 'Iuliu Hatieganu', Cluj-Napoca, Romania
}

Corresponding Author: Monica Hăşmăşanu, Assistant Lecturer, Department of Neonatology, Obstetrics and Gynecology I Clinic, Emergency Hospital, University of Medicine and Pharmacy, Clinicilor No 3-5 cod 400006, Cluj-Napoca, Romania Phone: +40741985974, e-mail: monica1082003@yahoo.com to the metastatic tumors, the primary ones are more frequent and most of them are benign. The most common types of heart tumors diagnosed in children are rhabdomyoma, teratoma and fibroma. ${ }^{3,4}$

The diagnosis can be established during fetal or postnatal life. Most fetal cardiac tumors are detectable in the late second or third trimester. ${ }^{3}$ In postnatal life, the manifestations of a cardiac tumor will vary according to its size and location. A large tumor may determine a compression of cardiac chambers or vital structures, leading to arrhythmias and obstruction of cardiac valves and subsequent obstruction of the tracts. ${ }^{5}$

The objective of this study was to analyze the clinical and echocardiographic features of cardiac tumors in the neonatal period.

\section{MATERIALS AND METHODS}

This is a retrospective study that assessed the development of newborns diagnosed with cardiac tumors.

We present five newborns with cardiac tumors diagnosed by echocardiography in the Neonatology Department of Obstetrics and Gynecology I Clinic Cluj-Napoca and evaluated in the Cardiology Institute in Cluj-Napoca between 2007 and 2012. During this period, there were 13,363 newborns in the institution.

All subjects had a clinical evaluation that included physical examination, echocardiography, electrocardiography and a chest X-ray.

\section{RESULTS}

Detailed demographic and clinical data of studied newborns are shown in Table 1.

Case 1 was a full-term male newborn, delivered by cesarean section, with a birth weight of $4100 \mathrm{gm}$ and an Apgar score of 9/10. The course of pregnancy was uneventful till the third trimester, when a tumor of the left ventricle, possibly rhabdomyoma, was visualized by ultrasound. Postnatal adaptation was without incidents. Postnatal echocardiography confirmed the presence of a mass in the left ventricle, with a diameter of 11/17.4 mm (Fig. 1), attached to the lateral wall and with a large implantation base, which seemed to cover the papillary muscle. The diagnosis was 
Table 1: Demographic and clinical characteristic of studied newborns

\begin{tabular}{|c|c|c|c|c|c|c|c|}
\hline Case no. & $\begin{array}{l}\text { Age at } \\
\text { diagnosis }\end{array}$ & Gender & Symptoms & $\begin{array}{l}\text { ECHO tumors } \\
\text { location/size }\end{array}$ & $\begin{array}{l}\text { Patho- } \\
\text { morphology }\end{array}$ & Follow-up & Diagnosis \\
\hline 1 & Prenatal & $M$ & Asymptomatic & $\begin{array}{l}\text { Tumor in left } \\
\text { ventricle/11/17.4 mm }\end{array}$ & - & 3 years & $\begin{array}{l}\text { Probably } \\
\text { rhabdomyoma } \\
\text { —decreased in } \\
\text { size }\end{array}$ \\
\hline 2 & 9 days & $\mathrm{F}$ & $\begin{array}{l}\text { Multiple organ } \\
\text { failure }\end{array}$ & $\begin{array}{l}\text { Multiple tumors in the } \\
\text { right ventricle with } \\
\text { diameters of } 7 \mathrm{~mm} \\
\text { causing outflow tract } \\
\text { obstruction }\end{array}$ & $\begin{array}{l}\text { Multiple } \\
\text { rhabdomyoma }\end{array}$ & $\begin{array}{l}\text { Died after } \\
24 \text { days }\end{array}$ & $\begin{array}{l}\text { Tuberous } \\
\text { sclerosis }\end{array}$ \\
\hline 3 & Prenatal & $\mathrm{M}$ & Asymptomatic & $\begin{array}{l}\text { Unique tumor } \\
(14 / 11.5 \mathrm{~mm}) \text { in the } \\
\text { left ventricle }\end{array}$ & - & $\begin{array}{l}\text { No } \\
\text { follow-up }\end{array}$ & $\begin{array}{l}\text { Probably } \\
\text { rhabdomyoma }\end{array}$ \\
\hline 4 & 1 day & $\mathrm{F}$ & $\begin{array}{l}\text { Respiratory } \\
\text { distress }\end{array}$ & $\begin{array}{l}\text { A } 4 / 7 \mathrm{~mm} \text { tumor } \\
\text { attached to the atrial } \\
\text { side of the tricuspid } \\
\text { valve }\end{array}$ & - & 1 year & $\begin{array}{l}\text { Probably } \\
\text { fibroelastoma }\end{array}$ \\
\hline 5 & 4 days & $\mathrm{F}$ & Asymptomatic & $\begin{array}{l}\text { Hyperechoic tumor, } \\
4-8 \mathrm{~mm} \text {, immobile in } \\
\text { the right atrium }\end{array}$ & - & $\begin{array}{l}\text { No } \\
\text { follow-up }\end{array}$ & $\begin{array}{l}\text { Probably } \\
\text { hemangioma }\end{array}$ \\
\hline
\end{tabular}

rhabdomyoma (Fig. 2). The patient did not present any skin lesion, arrhythmias or neurological abnormalities and was clinically and hemodynamically stable during monitoring. The abdominal and transfontanellar ultrasound showed no pathological elements. Subsequently, at the ages of 1 and 5 months, the patient was clinically and hemodynamically stable. At 1 month, no echocardiographic changes were observed; the tumor diameter was similar to that measured during the first examination $(10 / 17.5 \mathrm{~mm})$ (Fig. 3). At the age of 5 months, the size of the left ventricular tumor decreased to a diameter of $8 / 10 \mathrm{~mm}$ (Fig. 4). The tumor continued to decrease in size during the 4 years of follow-up.

Case 2 was a full-term female newborn, delivered in a local hospital with a birth weight of $3000 \mathrm{~g}$ and an Apgar

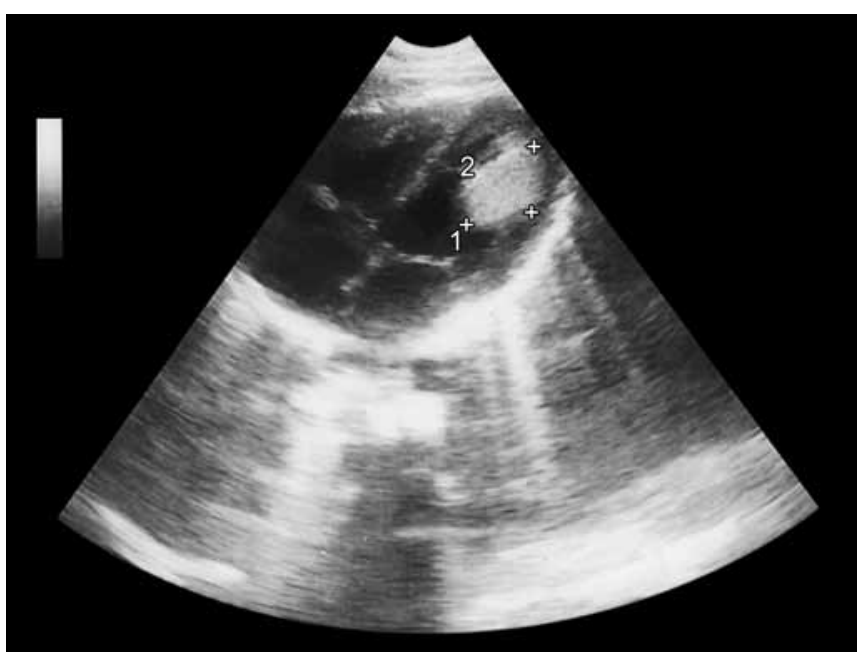

Fig. 1: Echocardiography-mass in the left ventricle, with a diameter of $11 / 17.4 \mathrm{~mm}$ score of 9/10. The baby girl had a family history (from the mother's side) of epilepsy, treated with carbamazepine, operated cleft lip and palate and mental retardation. At the age of 9 days, she was transferred to the Neonatology Department in Cluj-Napoca, with the suspicion of a congenital heart disease. At admission, the baby presented respiratory distress, cyanosis, grade II systolic murmur and hepatosplenomegaly. The laboratory tests showed high levels of cytolytic enzymes and severe thrombocytopenia and anemia, which were treated with red blood cell concentrate and platelet transfusions.

During the echocardiographic examination, multiple tumors in the right ventricle were observed, with diameters of approximately $7 \mathrm{~mm}$ obstructing the outflow tract. One

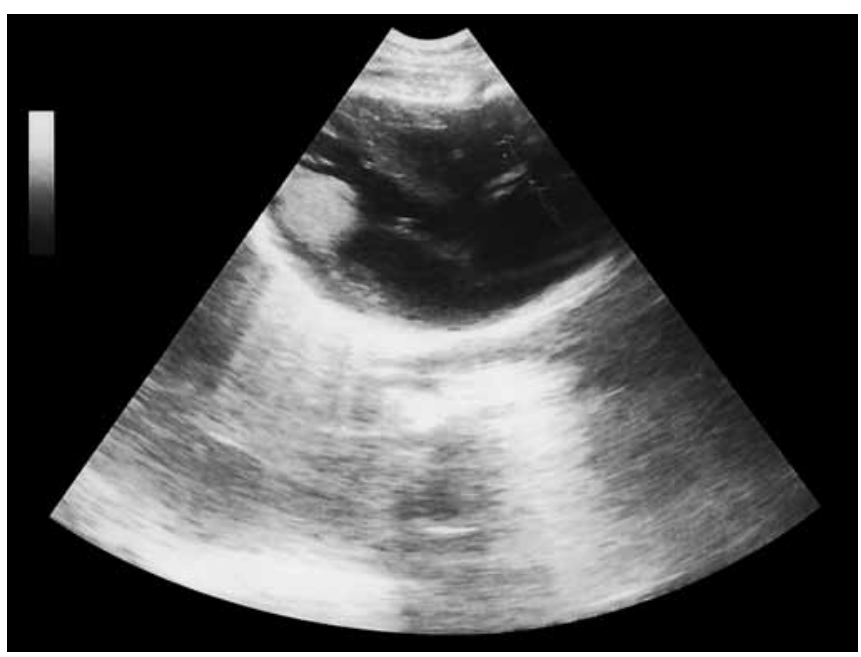

Fig. 2: Echocardiography—broad base of implantation that seems to cover the papillary muscle 


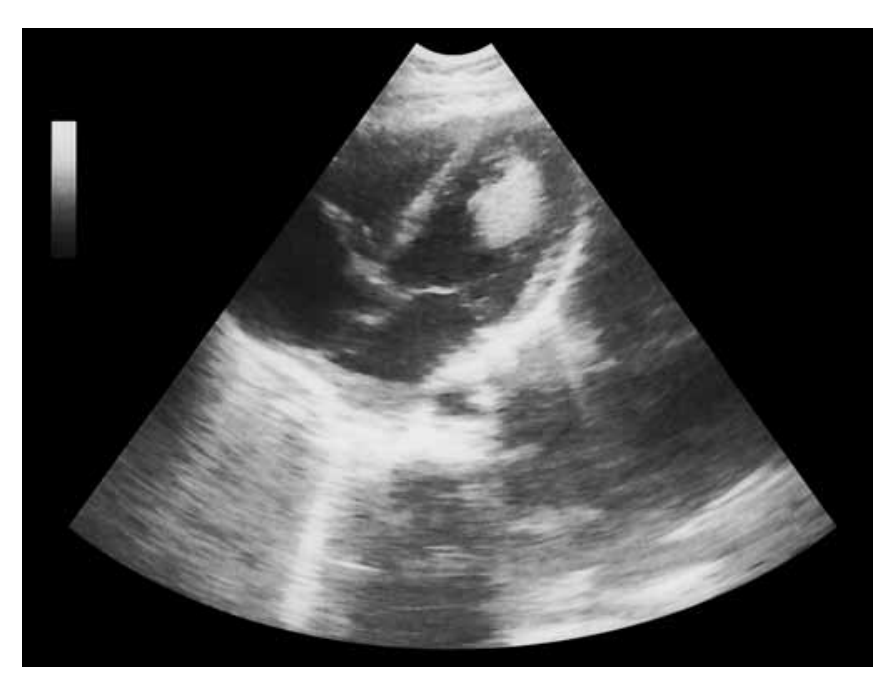

Fig. 3: Echocardiography-at the age of 1 month, the same aspect from the first examination

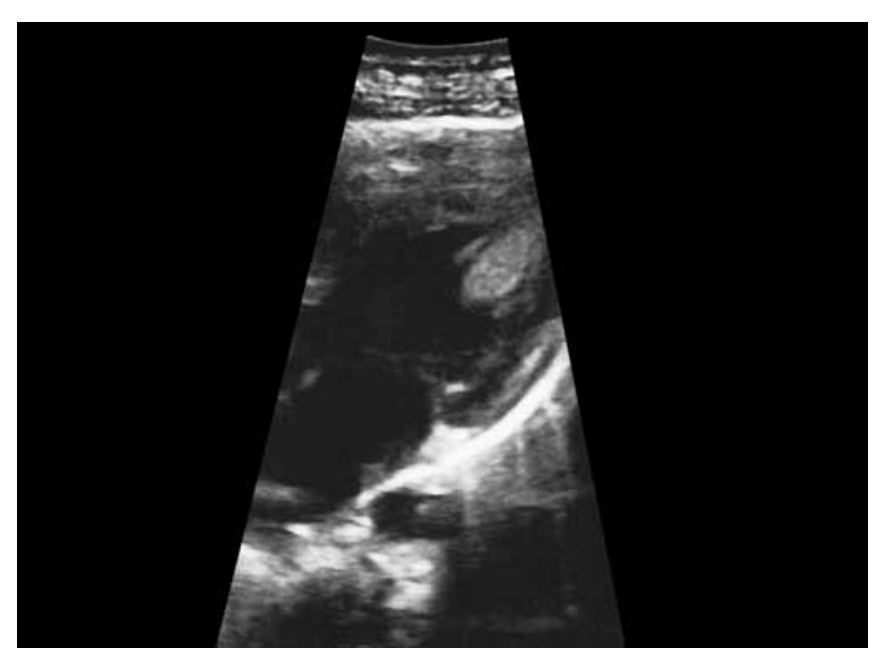

Fig. 4: Echocardiography-at the age of 5 months, tumor decreased in size, with a diameter of $8 / 10 \mathrm{~mm}$

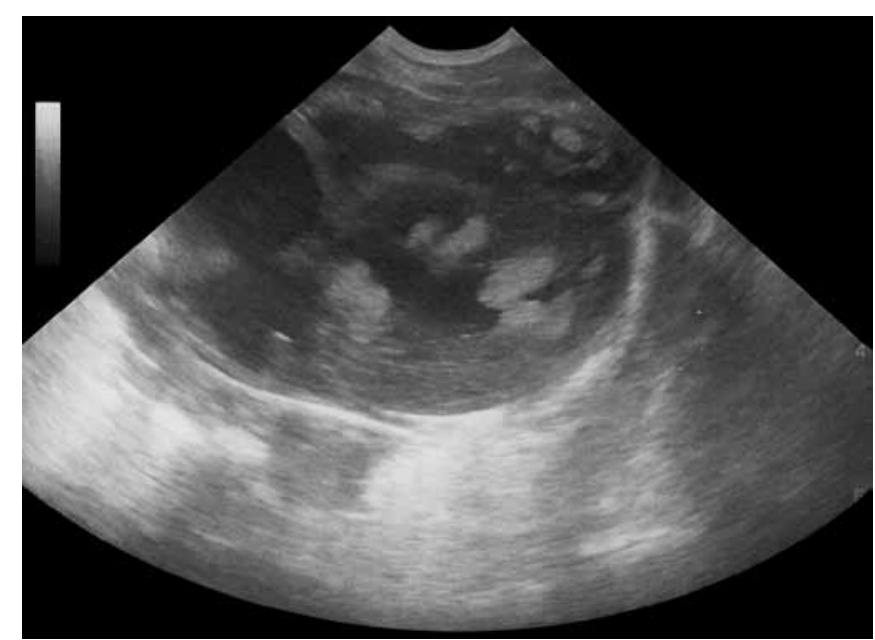

Fig. 5: Echocardiography-tumors, $6 / 10 \mathrm{~mm}$, attached to the interventricular septum, in the ejection route of the left ventricle

of the tumors, with a size of $6 / 10 \mathrm{~mm}$, was attached to the interventricular septum, in the ejection route of the left ventricle, and was causing severe obstruction with a maximum gradient of $80 \mathrm{~mm} \mathrm{Hg}$ (Fig. 5). Two other tumors of $6 / 7 \mathrm{~mm}$ were attached to the second portion of the interventricular septum and under the mitral valve (Fig. 6). These echocardiographic changes were suggestive for tuberous sclerosis (Fig. 7). Transfontanellar echography showed multiple nodular formations and ventriculomegaly (Fig. 8). For a complete evaluation, thoracic, abdominal and cranial magnetic resonance imaging (MRI) was performed. The cranial MRI showed multiple bilateral nodular formations with diameters between 0.5 and $2 \mathrm{~cm}$, located peri- and intraventricularly, also suggestive for tuberous sclerosis.

Because of multiple organ failure and severe anemia and thrombocytopenia, surgical intervention was contraindicated.

The evolution was unfavorable, the infant died within a few days of hospitalization. Anatomopathological examination confirmed tuberous sclerosis located in the heart and brain (Fig. 9).

Case 3 was a full-term newborn with prenatal diagnosis of a unique tumor of the left ventricle, possibly rhabdomyoma. Postnatally, the infant was hemodynamically stable, with no signs of neurological and skin abnormalities; echocardiography showed a unique tumor of $14 / 11.5 \mathrm{~mm}$ of the left ventricle, probably rhabdomyoma (Fig. 10). Abdominal and transfontanellar ultrasonography were normal for his age. Further development after discharge from the hospital is unknown because he was followed in a different medical department.

Case 4 was a newborn girl, delivered by cesarean section with an Apgar score of 6/8, after a physiological pregnancy. Postnatally, she presented cyanosis, grade IV systolic murmur and signs of respiratory distress. At 6 hours of age, she was transferred to the Neonatology Department in ClujNapoca. On admission, she presented with cyanosis, oxygen saturation was $85 \%$ (increased to $92 \%$ after oxygen therapy), signs of respiratory distress, blood pressure appropriate for the age, without significant differences between the four limbs. The laboratory tests showed leukocytosis $(36.6 \times$ $10^{9} / \mathrm{L}$ ) and a $\mathrm{pH}$ of 7.34 .

Echocardiography showed signs of pulmonary hypertension, with right to left shunt through the foramen ovale, small patent arterial duct, grade III tricuspid insufficiency and a $4 / 7 \mathrm{~mm}$ tumor attached to the atrial side of the tricuspid valve, most likely a fibroelastoma (Fig. 11).

Considering the signs of pulmonary hypertension (Fig. 12), treatment with Sildenafil and oxygen were initiated. After 6 days of treatment, the clinical evolution was favorable and echocardiography showed normal pressures in the pulmonary circulation, with little left to right shunting through the foramen ovale, grade III tricuspid insufficiency; the tumor attached to the tricuspid valve had characteristics 


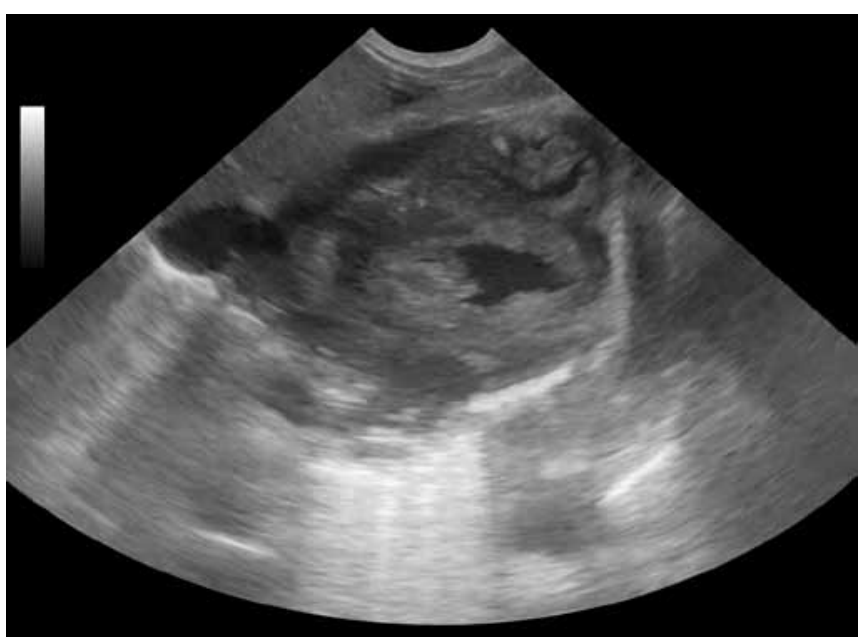

Fig. 6: Echocardiography-two other tumors of 6/7 mm attached to the second portion of the interventricular septum, the second one located under the mitral valve

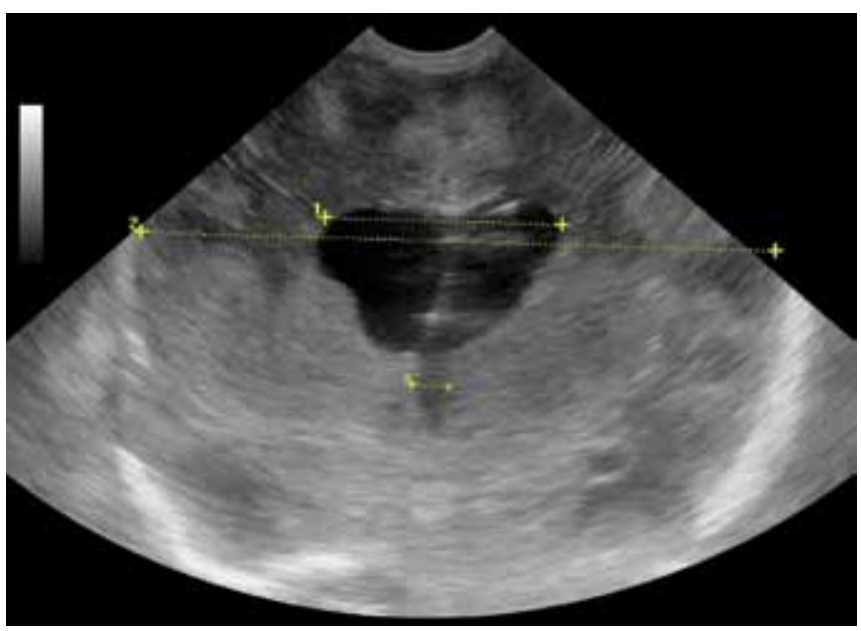

Fig. 8: Transfontanellar echography-multiple nodular formations and ventriculomegaly

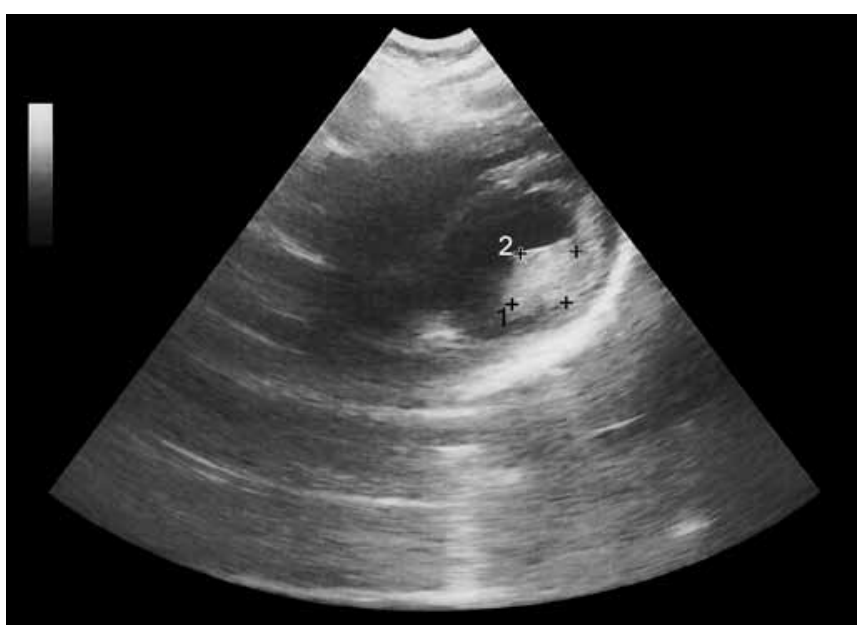

Fig. 10: Echocardiography—a unique tumor $(14 / 11.5 \mathrm{~mm})$ in the left ventricle

similar to those described at admission (Fig. 13). The patient was monitored in the department of neonatology until the age of 1 year and later in the cardiology outpatient clinic. During monitoring, the child remained hemodynamically stable.

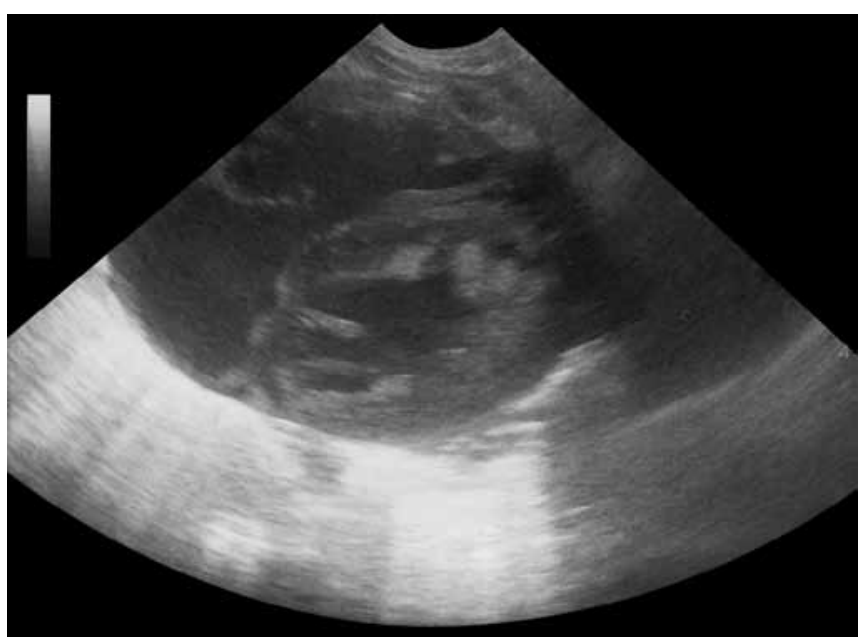

Fig. 7: Echocardiography-multiple tumors

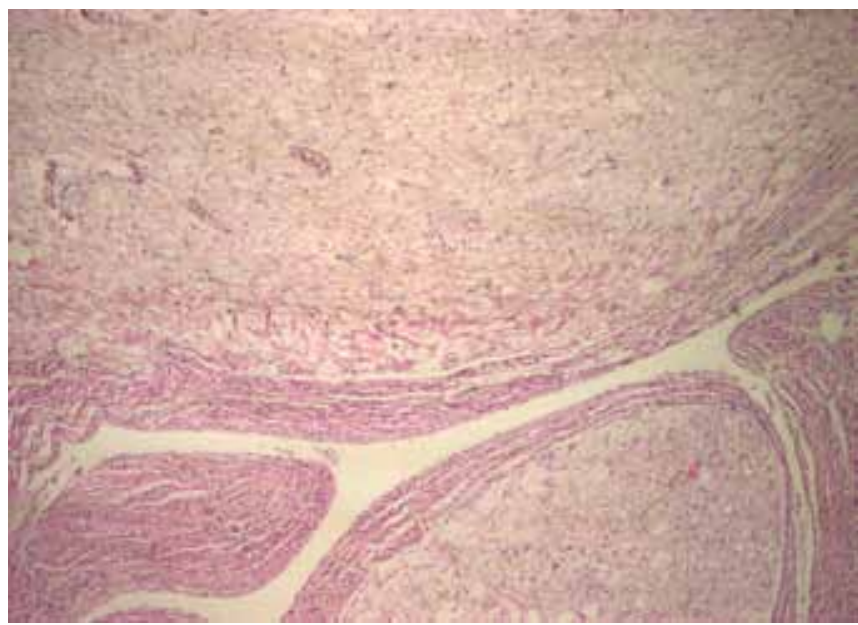

Fig. 9: Anatomopathologic examination—subendocardial rhabdomyoma

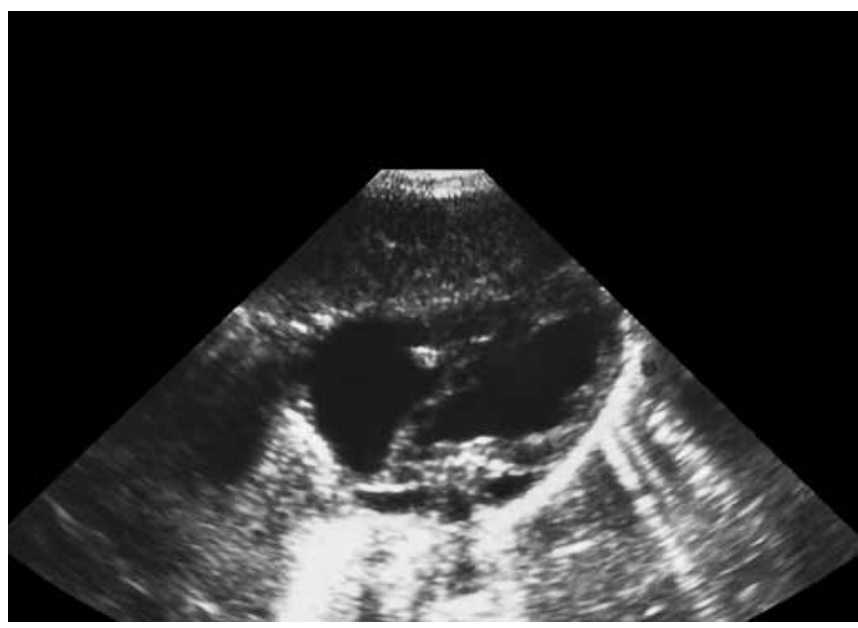

Fig. 11: Echocardiography - tumor attached to the atrial side of the tricuspid valve

Case 5 was a newborn from a mother with high-risk pregnancy due to an uncontrolled type 1 diabetes, previously incorrectly monitored. The infant was the sixth child. The newborn was delivered in cranial presentation, with a 


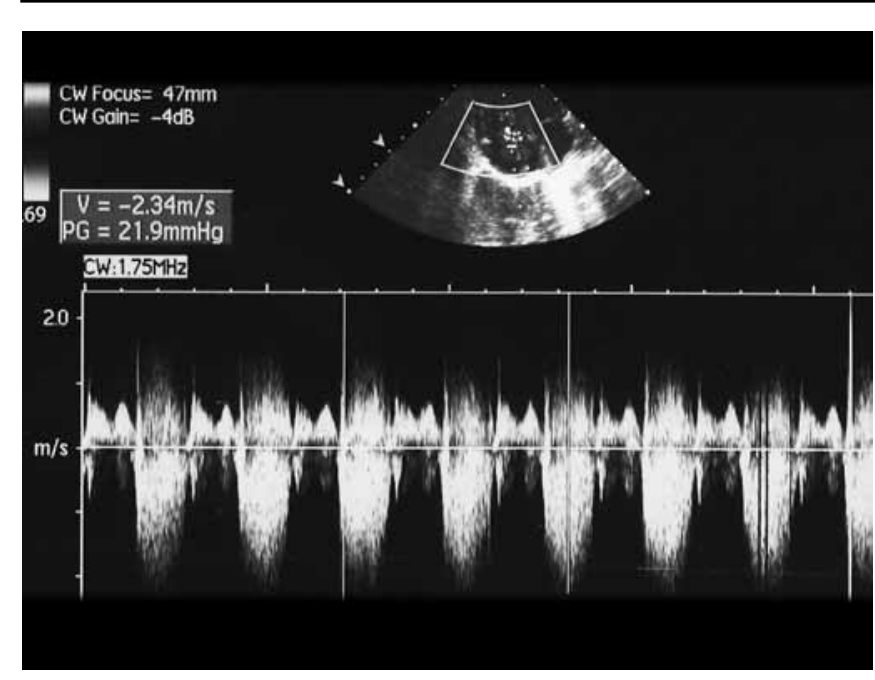

Fig. 12: Echocardiography—signs of pulmonary hypertension

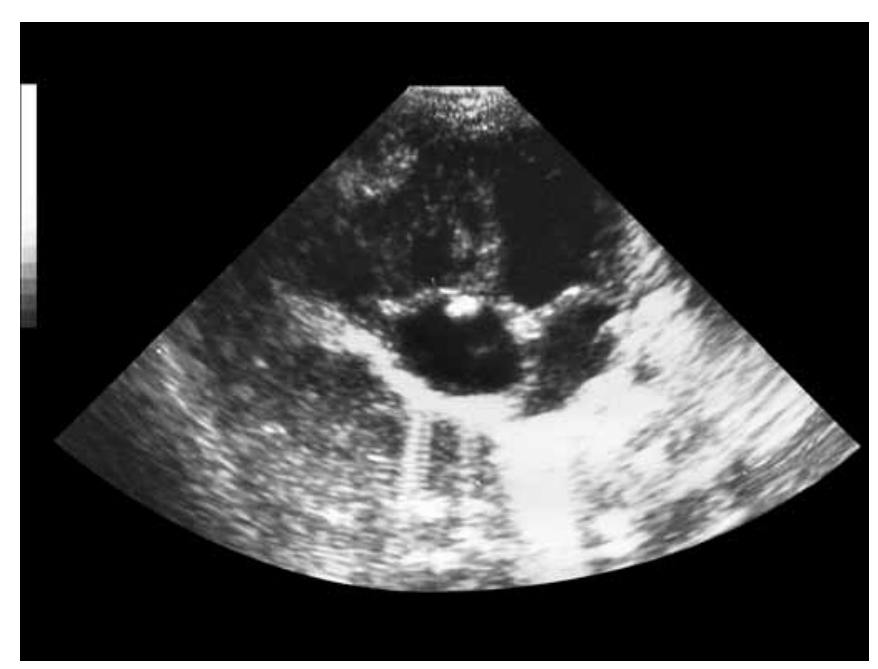

Fig. 13: Echocardiography-fibroelastoma

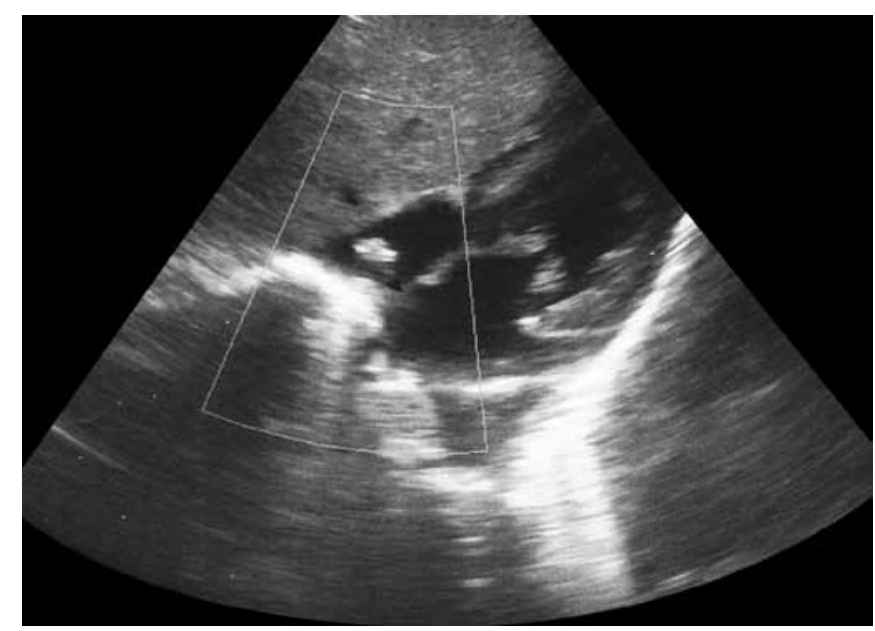

Fig. 14: Echocardiography—hyperechoic tumor, 4 to $8 \mathrm{~mm}$, immobile in the right atrium

birth weight of $4100 \mathrm{gm}$, with Apgar score of 7/9, transient tachypnea and required 114 hours of oxygen administration. It presented with neonatal hypoglycemia, which was corrected after carbohydrate intake.
The evolution was favorable and stable. The echocardiography revealed a hyperechoic, immobile tumor of 4 to $8 \mathrm{~mm}$ in the right atrium near the inferior vena cava, which was not obstructed. Hemangioma was suspected (Fig. 14). Further development after discharge is unknown because he did not attend any of his follow-up appointments.

\section{DISCUSSION}

Within 6 years, five cases of congenital cardiac tumors were diagnosed, two of them were rhabdomyomas.

Rhabdomyoma is the most common cardiac tumor diagnosed in childhood and represents more than $60 \%$ of all cardiac tumors. ${ }^{6}$ It presents as white, firm, well-circumscribed nodule, usually in the ventricular myocardium. In most cases, they are asymptomatic, except when the size compromises the hemodynamic or electrical function of the heart. ${ }^{7}$ The tumor may be discovered incidentally during echocardiography.

Only in two of the five presented cases, the diagnosis was made in utero. Prenatal echocardiography may detect rhabdomyomas in fetuses with tuberous sclerosis and provide important information for parents and healthcare providers. Additionally, genetic counseling is recommended for parents of patients with cardiac tumors.

In our cases, the clinical and echocardiographic appearance of a single tumor in the left ventricle in two patients (cases 1 and 3) was suggestive of rhabdomyoma. The presence of other tumors was excluded using abdominal and transfontanellar ultrasound examination. These procedures were performed because in $50 \%$ of infants with tuberous sclerosis cardiac rhabdomyomas could be found.

In the cases presented here, one spontaneous regression of the tumor was observed. It is known that, after birth, rhabdomyoma cells lose their ability to divide and the natural history of these tumors is regression. ${ }^{8}$ Complete resolution of more than $80 \%$ of the tumors may occur during early childhood. ${ }^{6}$ Thus, the disease can be managed conservatively and monitored by serial echocardiograms and ECGs. Surgical treatment is recommended only in cases with untreatable arrhythmias or when the tumor severely obstructs blood flow. ${ }^{7,9}$ The association of cardiac tumors with atrial or ventricular arrhythmias must be well documented. Although complete resection of the tumors is often currative, some tumor types may grow to incorporate coronary vascular and conduction tissue, making complete resection impossible. ${ }^{5}$

Tuberous sclerosis is an autosomal-dominant hamartomatosis caused by mutations in the TSC 1 and TSC 2 genes encoding hamartin and tuberin, proteins responsible for cell proliferation and suppression of tumor growth factors. ${ }^{10}$ It is associated with cardiac rhabdomyoma, childhood epilepsy, mental retardation and facial sebaceous adenomas. Multiple nodular lesions can be detected antepartum in 
the forebrain, cerebellum and brainstem. In the heart, multiple small, lobulated hyperechoic intramural masses may be observed by echocardiography. Clinical findings are not specific; tuberous sclerosis may present with murmur, cyanosis and arrhythmias. In the second case presented here, the association of multiple heart and brain formations were suggestive for the diagnosis of tuberous sclerosis. The evolution was unfavorable, the presence of severe hemodynamic disorders and biological status contraindicated the surgery and the patient died within 24 days after the birth.

Hemangiomas are benign primary cardiac tumors usually located in the ventricular septum and right atrium, histologically formed of blood vessels and rarely diagnosed during childhood. ${ }^{11}$ Clinical manifestations can include angina and congestive heart failure; the echocardiographical appearance is hyperechoic. Evolution may be spontaneous regression or hemorrhages.

The diagnosis of hemangioma in case 5 was an incidental one. The newborn presented signs of respiratory distress at birth, but with no abnormalities in the clinical evaluation, blood gases, biological parameters and chest radiography, and the case was initially diagnosed as neonatal transient tachypnea. Echocardiography was performed because the pregnancy was considered as a high risk: the mother had poorly controlled and monitored diabetes and maternal diabetes represents a risk factor for cardiomyopathy and septal hypertrophy in newborns. In our case, the cavity dimensions and interventricular septum were normal for the weight. An immobile tumor of $4 / 8 \mathrm{~mm}$ was observed in the left atrium, in the proximity of the inferior vena cava (not obstructed). The case was interpreted as a possible hemangioma that due to absence of symptoms required only echocardiographic follow-up. Further development after discharge from maternity is unknown.

Papillary fibroelastoma is rarely diagnosed in children. It is the most common primary tumor of cardiac valves. ${ }^{12}$ Clinical diagnosis can be difficult because embolic complications can mimic a variety of underlying diseases. Usually, the patients are asymptomatic, and diagnosis is often made in the context of embolic complications or in the context of an echocardiographic evaluation.

In the fourth case, that we presented, the diagnosis was established postnatally by echocardiography. Echocardiography showed a mobile mass with a short pedicle. The infant had signs of respiratory distress and pulmonary hypertension, but the evolution was favorable, with normalization of pressure in pulmonary circulation after treatment for pulmonary hypertension. The presence of the tricuspid valve tumor did not cause any hemodynamic issues or embolic complications, thus the medical attitude was regular monitoring of the patient.
It should be noted that early detection of cardiac tumors in fetuses may have a positive influence on the development of the newborns. ${ }^{13,14}$ Early identification with fetal echocardiography, associated with a complete postnatal evaluation, enables prompt postnatal treatment with lifesaving surgical resection of the mass when significant hemodynamic compromise or life-threatening arrhythmias are present. ${ }^{4,15,16}$

Genetic counseling is also required when we have a patient with cardiac tumors.

Tumors discovered incidentally may also be associated with other problems.

Surgical treatment after tumor detection may be useful to prevent embolic accidents and should be recommended for relieving clinical symptoms and removing of the mechanical obstruction of the blood flow. ${ }^{8}$

The prognosis for cardiac tumors is benign, if the patients do not develop arrhythmia or outflow obstruction. In symptomatic cases with non-myxomatous benign cardiac tumors, the prognosis is improved by surgical resection.

\section{CONCLUSION}

Cardiac tumors were rare in the studied population. Rhabdomyoma was the most frequently diagnosed and the cases had a good prognosis, the tumor being in regression.

Echocardiography was the investigation used for initial evaluation and may be the only diagnostic test needed to establish a diagnosis in selected patients.

\section{ACKNOWLEDGMENTS}

Authors wish to acknowledge the editorial support provided by Adriana Rusu (XPE Pharma and Science).

\section{REFERENCES}

1. Thiene G, Valente M, Lombardi M, Basso C. Tumours of the heart. In: Camm JA, Luscher TF, Serruys PV, editors. ESC Textbook of Cardiovascular Medicine. New York, NY: Oxford University Press 2009. p. 735-762.

2. Iacona GM, Barberb MA, Medina M, Abella R. Intrapericardial teratoma in a low birth weight preterm infant: a successful multidisciplinary approach. Interact Cardiovasc Thorac Surg 2011;12: 287-289.

3. Gazit AZ, Gandhi SK. Pediatric primary cardiac tumors: diagnosis and treatment. Curr Treat Options Cardiovasc Med 2007;9:399-406.

4. Isaacs $\mathrm{H}$ Jr. Fetal and neonatal cardiac tumors. Pediatr Cardiol 2004;25:252-273.

5. Myers KA, Wong KK, Tipple M, Sanatani S. Benign cardiac tumours, malignant arrythmias. Can J Cardiol 2010;26:e58-e61.

6. Uzun O, Wilson DG, Vujanic GM, Parsons JM, De Giovanni JV. Cardiac tumours in children. Orphanet J Rare Dis 2007;2:11-25.

7. Mariano A, Pita A, León R, Rossi R, Gouveia R, Teixeira A, Ferreira R, Anjos R, Menezes I, Martins FM. Primary cardiac tumors in children: a 16-year experience. Rev Port Cardiol 2009;28:279-288. 
8. Kohut J, Krzystolik-Ładzińska J, Szydłowski L, SmoleńskaPetelenz J, Giec-Fuglewicz G, Pajak J. The diagnosis, clinical course and follow-up of children with cardiac tumours-a single-center experience. Kardiol Pol 2010;68:304-309.

9. Castro FJ, Escudero. Tumores cardíacos. Protocolos diagnósticos y terapêuticos en Cardiología Pediátrica. Available at: http://www.aepe.es/.

10. Jóźwiak S, Kotulska K, Kasprzyk-Obara J, Domańska-Pakieła D, Tomyn-Drabik M, Roberts P, Kwiatkowski D. Clinical and genotype studies of cardiac tumors in 154 patients with tuberous sclerosis complex. Pediatrics 2006;118:e1146-e1151.

11. Eichler T, Paul T, Schneider HE. Hemangioma as a rare cause of a neonatal cardiac tumor resulting in inflow obstruction of the tricuspid valve. Clin Res Cardiol 2011;100:469-470.

12. Darvishian F, Farmer P. Papillary fibroelastoma of the heart: report of two cases and review of the literature. Ann Clin Sci 2001;31:291-296.
13. Jóźwiak S, Domańska-Pakieła D, Kwiatkowski DJ, Kotulska K. Multiple cardiac rhabdomyomas as a sole symptom of tuberous sclerosis complex: a case report with molecular confirmation. J Child Neurol 2005;20:988-989.

14. Chen CP, Su YN, Hung CC, Lee CN, Hsieh FJ, Chang TY, Chen MR, Wang W. Molecular genetic analysis of the TSC genes in two families with prenatally diagnosed rhabdomyomas. Prenat Diagn 2005;25:176-178.

15. De Rosa G, De Carolis MP, Pardeo M, Bersani I, Tempera A, De Nisco A, Caforio L, Romagnoli C, Piastra M. Neonatal emergencies associated with cardiac rhabdomyomas: an 8-year experience. Fetal Diagn Ther 2011;29:169-177.

16. Padalino MA, Vida VL, Bhattarai A, Reffo E, Milanesi O, Thiene G, Stellin G, Basso C. Giant intramural left ventricular rhabdomyoma in a newborn. Circulation 2011;124: 2275-2277. 